University of Wollongong

Research Online

Faculty of Engineering - Papers (Archive)

Faculty of Engineering and Information

Sciences

2003

\title{
Transport critical current density in Fe-sheathed nano-SiC doped MgB/sub
}

\section{2/ wires}

SX. Dou

University of Wollongong, shi@uow.edu.au

J. Horvat

University of Wollongong, jhorvat@uow.edu.au

Saeid Soltanian

University of Wollongong, saeid@uow.edu.au

Xiaolin Wang

University of Wollongong, xiaolin@uow.edu.au

M. J. Qin

University of Wollongong, qin@uow.edu.au

See next page for additional authors

Follow this and additional works at: https://ro.uow.edu.au/engpapers

Part of the Engineering Commons

https://ro.uow.edu.au/engpapers/34

\section{Recommended Citation}

Dou, S X.; Horvat, J.; Soltanian, Saeid; Wang, Xiaolin; Qin, M. J.; Zhou, S. H.; Liu, Hua-Kun; and Munroe, P. G.: Transport critical current density in Fe-sheathed nano-SiC doped MgB/sub 2/ wires 2003.

https://ro.uow.edu.au/engpapers/34

Research Online is the open access institutional repository for the University of Wollongong. For further information contact the UOW Library: research-pubs@uow.edu.au 


\section{Authors}

S X. Dou, J. Horvat, Saeid Soltanian, Xiaolin Wang, M. J. Qin, S. H. Zhou, Hua-Kun Liu, and P. G. Munroe 


\title{
Transport Critical Current Density in Fe-Sheathed Nano-SiC Doped $\mathrm{MgB}_{2}$ Wires
}

\author{
Shi X. Dou, Joseph Horvat, Saeid Soltanian, Xiao L. Wang, Meng J. Qin, Shi H. Zhou, Hua K. Liu, and \\ Paul G. Munroe
}

\begin{abstract}
The nano-SiC doped $\mathrm{MgB}_{2} / \mathrm{Fe}$ wires were fabricated using a powder-in-tube method and an in-situ reaction process. The depression of $T_{c}$ with increasing $\mathrm{SiC}$ doping level remained rather small due to the counterbalanced effect of $\mathrm{Si}$ and $\mathrm{C}$ co-doping. The high level $\mathrm{SiC}$ co-doping allowed creation of the intra-grain defects and nano-inclusions, which act as effective pinning centers, resulting in a substantial enhancement in the $J_{c}(H)$ performance. The transport $J_{c}$ for all the wires is comparable to the magnetic $J_{c}$ at higher fields despite the low density of the samples and percolative nature of current. The transport $I_{c}$ for the $10 \mathrm{wt} \% \mathrm{SiC}$ doped $\mathrm{MgB}_{2} / \mathrm{Fe}$ reached $660 \mathrm{~A}$ at $5 \mathrm{~K}$ and $4.5 \mathrm{~T}\left(J_{c}=133000 \mathrm{~A} / \mathrm{cm}^{2}\right)$ and $540 \mathrm{~A}$ at $20 \mathrm{~K}$ and $2 \mathrm{~T}\left(J_{c}=108000 \mathrm{~A} / \mathrm{cm}^{2}\right)$. The transport $J_{c}$ for the $10 \mathrm{wt} \% \mathrm{SiC}$ doped $\mathrm{MgB}_{2}$ wire is more than an order of magnitude higher than for the state-the-art Fe-sheathed $\mathrm{MgB}_{2}$ wire reported to date at $5 \mathrm{~K}$ and $10 \mathrm{~T}$ and $20 \mathrm{~K}$ and $5 \mathrm{~T}$ respectively. There is a plenty of room for further improvement in $J_{c}$ as the density of the current samples is only $50 \%$.
\end{abstract}

Index Terms-Critical current, magnesium diboride, nano-particle doping, silicon carbide.

\section{INTRODUCTION}

I T HAS BEEN established that Fe sheath is suitable for fabrication of $\mathrm{MgB}_{2}$ wires using a powder-in-tube method [1], [2]. Extensive research efforts have been made to improve the $J_{c}$ of Fe-sheathed $\mathrm{MgB}_{2}$ wires [1]-[5]. However, the $J_{c}$ performance in high fields and temperatures above $20 \mathrm{~K}$ remains unsatisfactory for many applications due to the poor pinning ability of this material. Attempts to enhance flux pinning have resulted in an encouraging improvement in irreversibility fields $\left(H_{i r r}\right)$ and $J_{c}(H)$ by oxygen alloying in $\mathrm{MgB}_{2}$ thin films [6] and by proton irradiation of $\mathrm{MgB}_{2}$ powder [7]. However, these techniques are not readily available for introducing effective pinning centers into $\mathrm{MgB}_{2}$ wires. Chemical doping has been commonly used to introduce flux pinning centers into a superconductor for enhancing critical current density. Unfortunately, chemical doping of $\mathrm{MgB}_{2}$ reported so far is limited to addition, rather than sub-

Manuscript received October 6, 2001. This work was supported in part by the Australia Research Council, Hyper Tech Research Inc., U.S. and Alphatech International Ltd.

S. X. Dou is with the Institute for Superconducting and Electronic Materials, University of Wollongong, Wollongong, NSW 2522 Australia (e-mail: shi_dou@uow.edu.au).

J. Horvat, S. Soltanian, X. L. Wang, M. J. Qin, S. H. Zhou, and H. K. Liu are with University of Wollongong, Wollongong, NSW 2522 Australia (e-mail: jhorvat@uow.edu.au; ss27@uow.edu.au; xiaolin@uow.edu.au; qin@uow.edu.au; sz03@uow.edu.au; hua_liu@uow.edu.au).

P. G. Munroe is with the Electron Microscope Unit, University of New South Wales, NSW 2001 Australia (e-mail: p.munroe@unsw.edu.au).

Digital Object Identifier 10.1109/TASC.2003.812196 stitution of the elements. The additives alone appear to be ineffective for improving pinning at high temperatures [8]-[10].

Recently, we found that chemical doping with nano-particle $\mathrm{SiC}$ into $\mathrm{MgB}_{2}$ can significantly enhance $J_{c}$ in high fields with only slight reduction in $T_{c}$ up to the doping level of $40 \%$ of B [11]. This finding clearly demonstrated that co-substitution of $\mathrm{SiC}$ for $\mathrm{B}$ in $\mathrm{MgB}_{2}$ induced intra-grain defects and high density of nano-inclusions as effective pinning centers, responsible for the improved performance of $J_{c}(H)$ in wide range of temperatures [12]. However, all the results reported thus far have been limited to magnetic measurements. As the materials are far from optimum and the sample density was only $50 \%$ of theoretical value the current in such a porous material is highly percolative. The major concern is whether the material can carry large transport $J_{c}$. In this work, we focus our study on the transport current and its field dependence for the nanometer-size $\mathrm{SiC}$ doped $\mathrm{MgB}_{2}$ wires. Our results reveal that the nanometer size $\mathrm{SiC}$ doped $\mathrm{MgB}_{2} / \mathrm{Fe}$ wires can carry higher transport $I_{c}$ and $J_{c}$ in the magnetic fields ever reported for any form of $\mathrm{MgB}_{2}$. SiC doped $\mathrm{MgB}_{2}$ is very promising for many applications, as this chemical doping is a readily achievable and economically viable process to introduce effective flux pinning.

\section{EXPERIMENTAL DETAILS}

A standard powder-in-tube method was used for the Fe clad $\mathrm{MgB}_{2}$ tape [2]. Powders of magnesium (99\%) and amorphous boron $(99 \%)$ were well mixed with 0 and $10 \mathrm{wt} \%$ of SiC nanoparticle powder (size of $10 \mathrm{~nm}$ to $20 \mathrm{~nm}$ ) and thoroughly ground. The pure Fe tube had an outside diameter (OD) of $10 \mathrm{~mm}$, a wall thickness of $1 \mathrm{~mm}$, and was $10 \mathrm{~cm}$ long with one end of the tube sealed. The mixed powder was filled in to the tube and the remaining end was crimped by hand. The composite was drawn to a $1.4 \mathrm{~mm}$ diameter wire 2 meters long. Several short samples $2 \mathrm{~cm}$ in length were cut from the wire. These pieces were then sintered in a tube furnace over a temperature range from $800-850{ }^{\circ} \mathrm{C}$ for $10 \mathrm{~min}$ to $30 \mathrm{~min}$. This was followed by furnace cooling to room temperature. A high purity argon gas flow was maintained throughout the sintering process.

Transport current was measured using pulse DC method. A pulse of the current was obtained by discharging a capacitor through the sample, coil of thick copper wire and noninductive resistor connected in series. The current was measured via the voltage drop on the noninductive resistor of $0.01 \mathrm{Ohm}$. The current reached its maximum value $(700 \mathrm{~A})$ within $1 \mathrm{~ms}$. The voltage developed on the sample was measured simultaneously with the current, using a 2-channel digital oscilloscope. Because both 


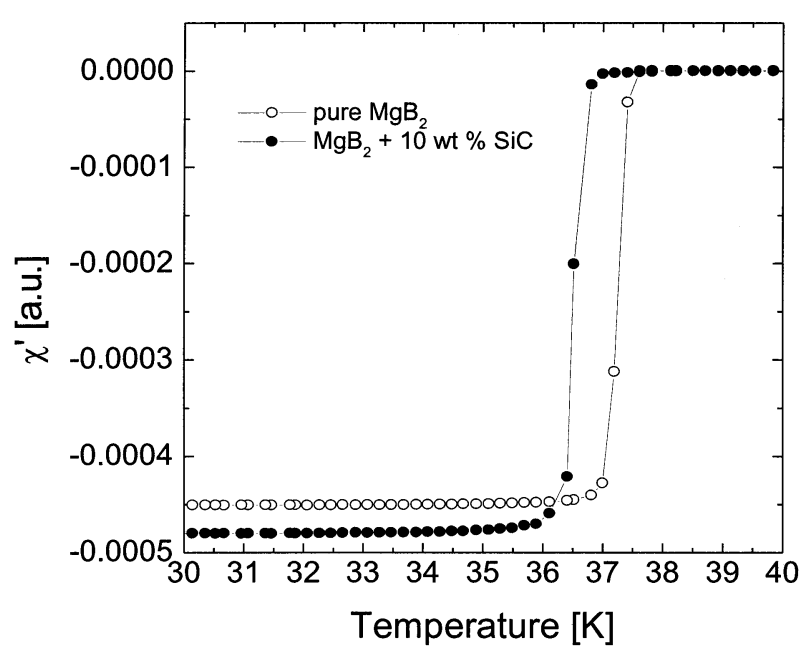

Fig. 1. Critical transition temperature $\left(T_{c}\right)$ measured using magnetic susceptibility versus temperature for pure $\mathrm{MgB}_{2}$ and $10 \mathrm{wt} \% \mathrm{SiC}$ doped $\mathrm{MgB}_{2} / \mathrm{Fe}$ wires.

channels of the oscilloscope had the same ground, the signal from the voltage taps was first fed to a transformer preamplifier (SR554). This decoupled the voltage taps from the resistor used for measuring the current, thereby avoiding creation of the ground loops and parasitic voltages in the system, as well as of an additional current path in parallel to the sample. The transformer amplified the voltage 100 times, improving the sensitivity of the experiment. Magnetic field was produced by a $12 \mathrm{~T}$ superconducting magnet. Sample mounting allowed for orienting the field either perpendicular to the wire, or parallel to it. In the later case, the field was also parallel to the current passing through the sample. The sample was placed into a continuous flow helium cryostat, allowing the control of temperature better than $0.1 \mathrm{~K}$.

The magnetization of samples was measured over a temperature range of 5 to $30 \mathrm{~K}$ using a Physical Property Measurement System (PPMS, Quantum Design) with a sweep rate of magnetic field of $50 \mathrm{Oe} / \mathrm{s}$ and amplitude up to 8.5T. Samples are in the form of bars cut from the pellets which were processed under the same conditions as the wires. All the samples had the same size of $0.56 \times 2.17 \times 3.73 \mathrm{~mm}^{3}$. A magnetic $J_{c}$ was derived from the height of the magnetization loop using Bean's model.

\section{RESULTS AND DISCUSSION}

Fig. 1 shows the transition temperature $\left(T_{c}\right)$ for the doped and undoped samples determined by ac susceptibility measurements. The $T_{c}$ obtained as the onset of magnetic screening for the undoped sample was $37.6 \mathrm{~K}$. For the $10 \mathrm{wt} \% \mathrm{SiC}$ doped sample, the $T_{c}$ decreased only for $0.7 \mathrm{~K}$. In contrast, the $T_{c}$ was depressed by almost $7 \mathrm{~K}$ for $10 \% \mathrm{C}$ substitution for B in $\mathrm{MgB}_{2}$ [13]. This suggests that the higher tolerance of $T_{c}$ of $\mathrm{MgB}_{2}$ to $\mathrm{SiC}$ doping is attributable to the counterbalance effect of the co-doping by $\mathrm{C}$ and $\mathrm{Si}$. This is because the average size of $\mathrm{C}$ $(0.077 \mathrm{~nm})$ and $\mathrm{Si}(0.11 \mathrm{~nm})$ atoms is close to that of B (0.097 $\mathrm{nm})$. As reported previously, the $10 \mathrm{wt} \% \mathrm{SiC}$ doped sample consists of major phase with $\mathrm{MgB}_{2}$ structure and minority phases: $\mathrm{Mg}_{2} \mathrm{Si}$ and $\mathrm{MgO}$ which occupied about $10 \%$ to $15 \%$ volume fraction.

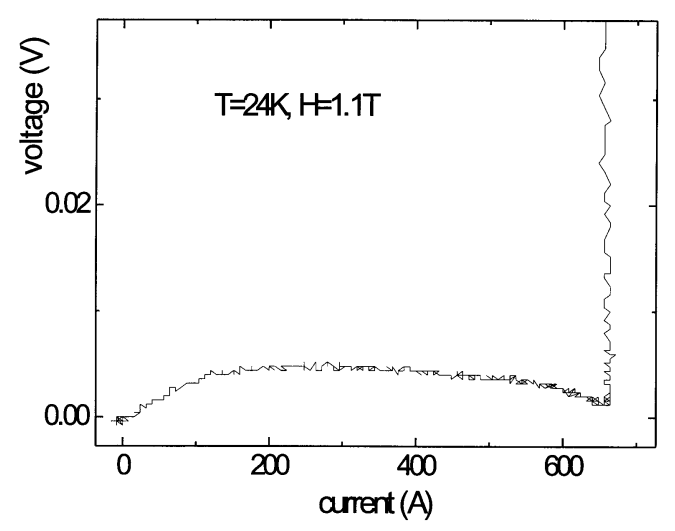

Fig. 2. $I-V$ curve for nondoped $\mathrm{MgB}_{2} / \mathrm{Fe}$ wire. $I_{c}=665 \mathrm{~A}$ at $24 \mathrm{~K}$ and $1.1 \mathrm{~T}$.

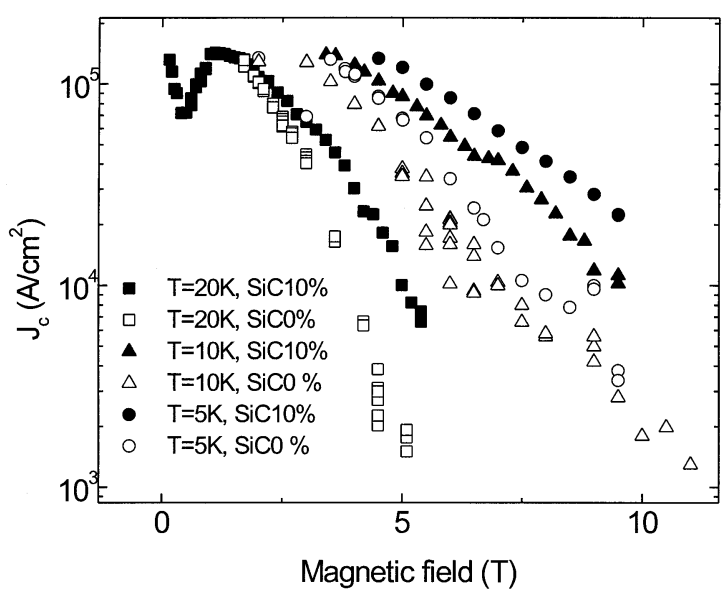

Fig. 3. Transport $J_{c}-H$ dependence at $5 \mathrm{~K}, 10 \mathrm{~K}$ and $20 \mathrm{~K}$ for the pure $\mathrm{MgB}_{2} / \mathrm{Fe}$ and $10 \mathrm{wt} \% \mathrm{SiC}$ doped $\mathrm{MgB}_{2} / \mathrm{Fe}$ wires.

Fig. 2 shows a typical $V-I$ characteristic for the $\mathrm{MgB}_{2} / \mathrm{Fe}$ wire. It is noted that the self-field of the current pulse induced a voltage in the voltage taps, which gave a background voltage. It was easy to distinguish the voltage created by the superconductor on this background, because the voltage developed very abruptly when the current reached the value of $I_{c}$. It is interesting to note that the total current that the wire can carry reached $665 \mathrm{~A}$ at $24 \mathrm{~K}$ and $1.1 \mathrm{~T}$. The transport $I_{c}$ for the $10 \mathrm{wt} \%$ $\mathrm{SiC}$ doped $\mathrm{MgB}_{2} / \mathrm{Fe}$ reached $660 \mathrm{~A}$ at $5 \mathrm{~K}$ and $4.5 \mathrm{~T}$ and $540 \mathrm{~A}$ at $20 \mathrm{~K}$ and $2 \mathrm{~T}$. Due to the limitation of our power source all the $I_{c}$ measurements were limited to the maximum 700A.

Fig. 3 shows the $J_{c}(H)$ curves for the undoped and the $10 \mathrm{wt} \% \mathrm{SiC}$-doped $\mathrm{MgB}_{2}$ samples at $5 \mathrm{~K}, 10 \mathrm{~K}$, and $20 \mathrm{~K}$. It is noted that all the $J_{c}(H)$ for $10 \mathrm{wt} \% \mathrm{SiC}$ doped $\mathrm{MgB}_{2} / \mathrm{Fe}$ wire are significantly higher than the undoped sample at higher fields. The transport $J_{c}$ for the $10 \mathrm{wt} \%$ doped $\mathrm{MgB}_{2} / \mathrm{Fe}$ reached $133000 \mathrm{~A} / \mathrm{cm}^{2}$ at $5 \mathrm{~K}$ and $4.5 \mathrm{~T}$ and $108000 \mathrm{~A} / \mathrm{cm}^{2}$ at $20 \mathrm{~K}$ and $2 \mathrm{~T}$. The transport $J_{c}$ for the $10 \mathrm{wt} \% \mathrm{SiC}$ doped $\mathrm{MgB}_{2}$ wire increased by a factor of 6 at $5 \mathrm{~K}$ and $9 \mathrm{~T}$, and $20 \mathrm{~K}$ and $5 \mathrm{~T}$ respectively, compared to the undoped wire. These results indicate that $\mathrm{SiC}$ doping strongly enhanced the flux pinning of $\mathrm{MgB}_{2}$ in magnetic fields. The enhancement of pinning by $\mathrm{SiC}$ doping is also evident from the pinning force density versus magnetic filed as shown in Fig. 4. The volume pinning force density of $5.5 \mathrm{GN} / \mathrm{m}^{3}$ at $20 \mathrm{~K}$ is comparable to that of $\mathrm{NbTi}$ at $4.2 \mathrm{~K}$. Although the maximum pinning force density only has a 


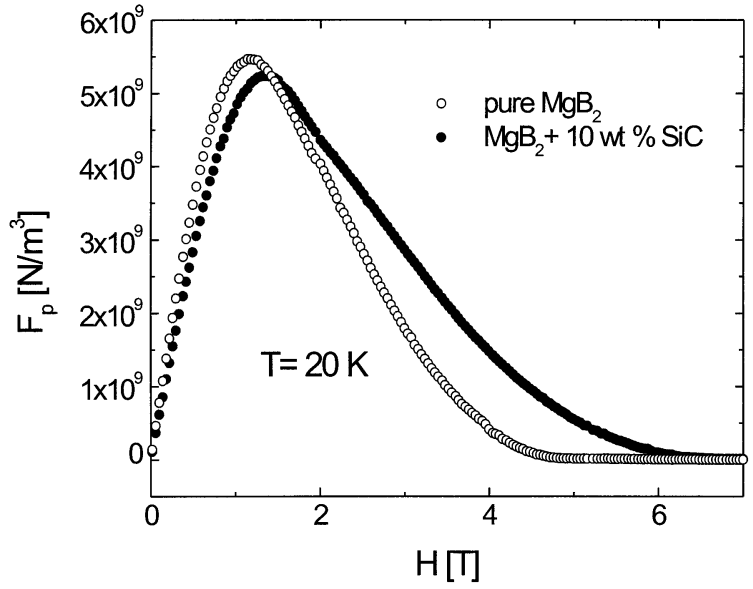

Fig. 4. Pinning force density versus magnetic filed for the undoped and $10 \mathrm{wt} \%$ $\mathrm{SiC}$ doped $\mathrm{MgB}_{2} / \mathrm{Fe}$ wires.
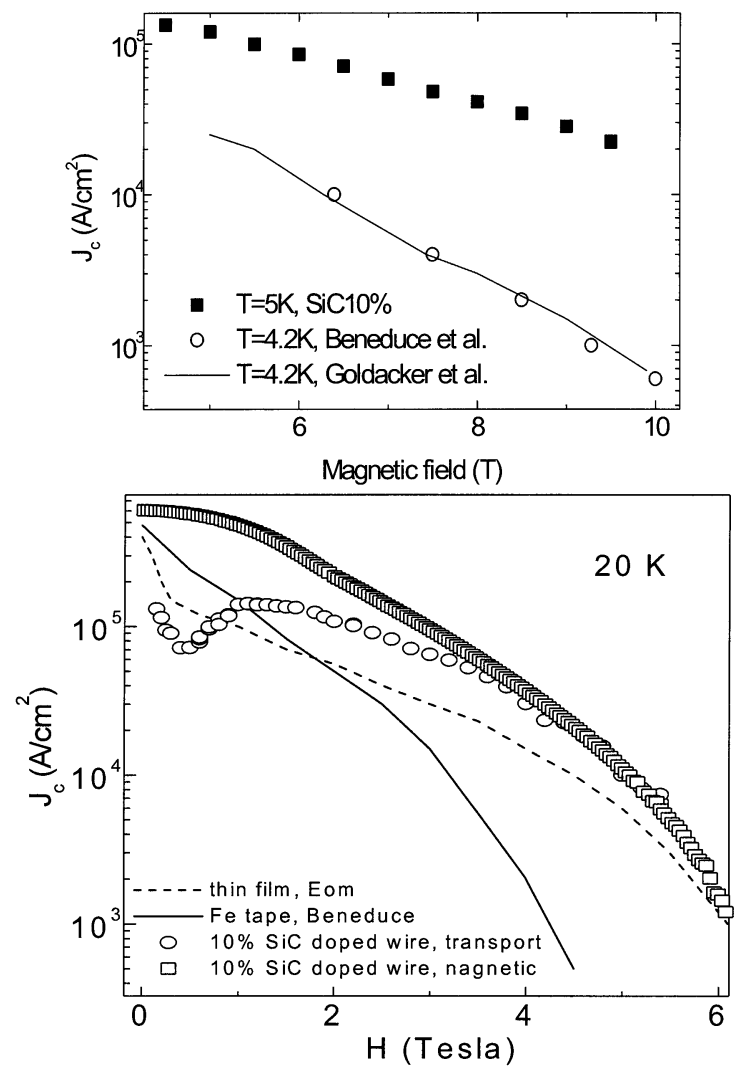

Fig. 5. Comparison of the transport $J_{c}$ with magnetic $J_{c}$ for the $10 \mathrm{wt} \% \mathrm{SiC}$ doped $\mathrm{MgB}_{2} / \mathrm{Fe}$ wire, including the best transport $J_{c}$ of a strongly pinned thin film by Eom et al., [8] and Fe-sheathed $\mathrm{MgB}_{2}$ tape by Goldacher et al., [3] and Beneduce et al., [14].

little shift to higher field, the pinning force density for the $\mathrm{SiC}$ doped $\mathrm{MgB}_{2} / \mathrm{Fe}$ wire is clearly greater than for the undoped wire at field above $1.5 \mathrm{~T}$.

Fig. 5 shows the comparison of the transport $J_{c}$ with magnetic $J_{c}$. Although there is quite different voltage standard for measuring the transport $J_{c}$ and magnetic $J_{c}$, due to steep $V-I$ characteristics, $J_{c}$ is expected to be similar for both methods. It is noted that the transport $J_{c}$ is lower than magnetic $J_{c}$ in low fields as the transport $J_{c}$ showed some type of "peak effect." The peak effect originates from the interaction between the $\mathrm{Fe}$

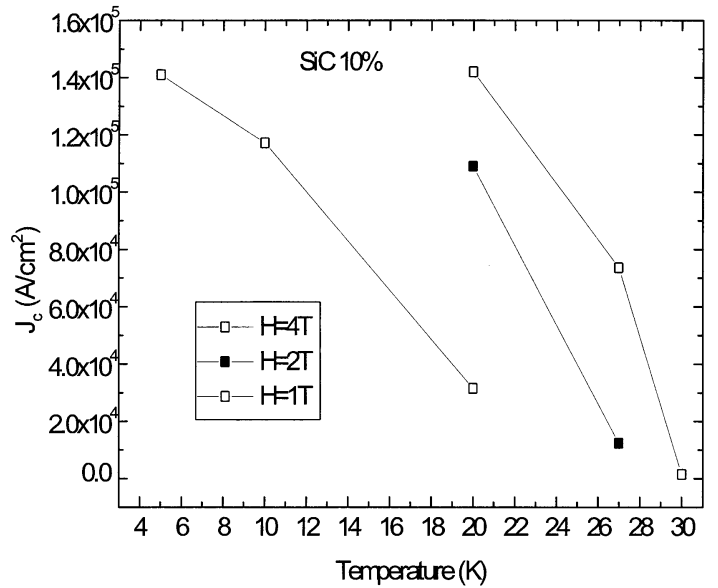

Fig. 6. $J_{c}(H)$ versus temperature for the $10 \mathrm{wt} \% \mathrm{SiC}$ doped $\mathrm{MgB}_{2}$ wire at $1 \mathrm{~T}$, $2 \mathrm{~T}$ and $4 \mathrm{~T}$.

sheath and superconductor. However, the transport $J_{c}$ for the wires is comparable to or higher than the magnetic $J_{c}$ at higher fields despite the low density of the samples and percolative nature of current. Fig. 5 also shows a comparison of the transport $J_{c}(H)$ for $10 \mathrm{wt} \% \mathrm{SiC}$ doped $\mathrm{MgB}_{2} / \mathrm{Fe}$ wire with the thin film [6] and the Fe-sheathed $\mathrm{MgB}_{2}$ tape at $5 \mathrm{~K}$ and $20 \mathrm{~K}$ [3], [14] reported previously. We see the $J_{c}$ for the $10 \mathrm{wt} \% \mathrm{SiC}$ doped wire is more than an order of magnitude higher than the best transport $J_{c}$ reported in $\mathrm{Fe}-\mathrm{MgB}_{2}$ tape at $5 \mathrm{~K}$ and $8 \mathrm{~T}$ and $20 \mathrm{~K}$ and $4 \mathrm{~T}$ respectively. It is even comparable to the strongly pinned thin film (magnetic $J_{c}$ for the thin film) at 20K. This is the best transport $J_{c}-H$ performance ever reported for $\mathrm{MgB}_{2}$ in any form.

Fig. 6 shows the $J_{c}(H)$ versus temperature for $10 \mathrm{wt} \% \mathrm{SiC}$ doped wire at 1T, 2T and 4T. With SiC doping, we can achieve $J_{c}$ values from $50000 \mathrm{~A} / \mathrm{cm}^{2}$ to $150000 \mathrm{~A} / \mathrm{cm}^{2}$ in temperature range between $15 \mathrm{~K}$ and $25 \mathrm{~K}$ and field range of $2 \mathrm{~T}$ to $5 \mathrm{~T}$. These results demonstrate that the nano-SiC doping into $\mathrm{MgB}_{2} / \mathrm{Fe}$ wire makes a number of applications practical, including MRI, moderate magnets, magnetic windings for energy storage, magnetic separators, transformers, levitation, motors and generators. The $\mathrm{SiC}$ substituted $\mathrm{MgB}_{2} / \mathrm{Fe}$ wire is attractive from the economic point of view. The main cost for making $\mathrm{MgB}_{2}$ conductors will be the high purity B. Furthermore, the SiC doping has already shown a significant benefit by enhancing flux pinning. It is evident that the future $\mathrm{MgB}_{2}$ conductors will be made using a formula of $\mathrm{MgB}_{x} \mathrm{Si}_{y} \mathrm{C}_{z}$ instead of pure $\mathrm{MgB}_{2}$.

Fig. 7 is TEM image of Sic-doped $\mathrm{MgB}_{2}$ showing a very high density of dislocations and massive nano-meter size inclusions inside the grains 7(a)). These inclusions are most likely the $\mathrm{Mg}_{2} \mathrm{Si}$ as this is the major impurity phase picked up by the XRD analysis. The EDS analyses showed that the grains consisted of $\mathrm{Mg}, \mathrm{B}, \mathrm{C}, \mathrm{Si}$ and $\mathrm{O}$. The presence of oxygen within the grain is consistent with the results obtained from a thin film with strong pinning where the ratio of $\mathrm{Mg}: \mathrm{B}: \mathrm{O}$ reached $1.0: 0.9: 07$ [6]. All the intra-grain defects and the inclusions within the grains act as effective pinning centers, responsible for the enhanced flux pinning.

The present study for optimization is only limited by the processing conditions, the density of the Fe-sheathed $\mathrm{MgB}_{2}$ wires is still very low, only about 1.2 to $1.3 \mathrm{~g} / \mathrm{cm}^{3}$. Thus, a higher $J_{c}$ 


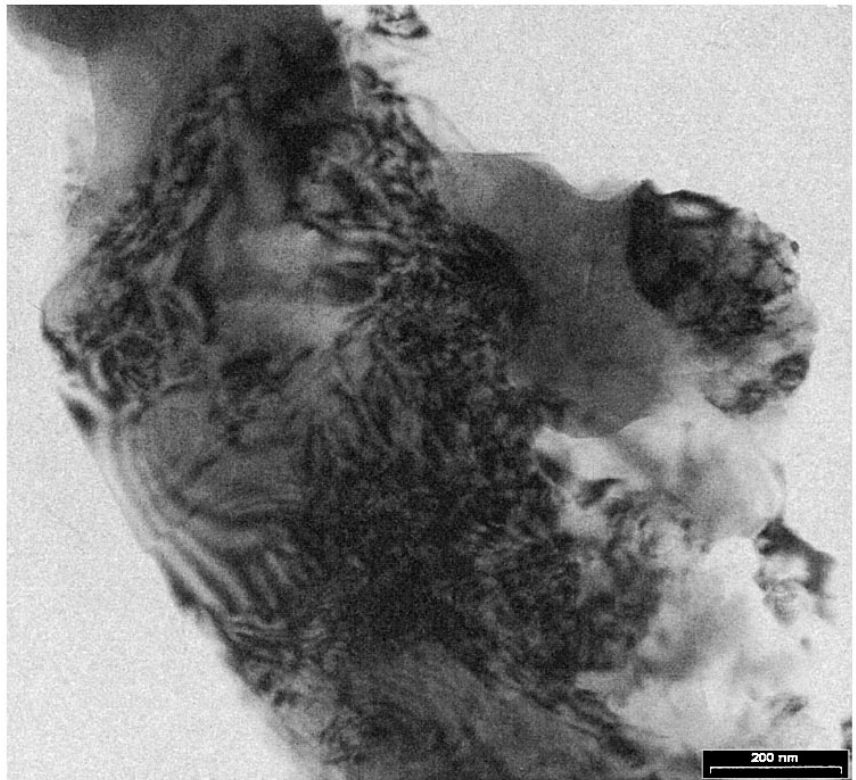

Fig. 7. TEM image for the undoped and $10 \mathrm{wt} \% \mathrm{SiC}$ doped $\mathrm{MgB}_{2} / \mathrm{Fe}$ wires.

and better flux pinning enhancement can be achieved if the density of the samples is further improved.

\section{CONCLUSION}

In summary, we have further demonstrated that very high transport critical current and current density of Fe-sheathed $\mathrm{MgB}_{2}$ wires can be achieved by a readily achievable and economically viable chemical doping with nano-SiC. $J_{c}$ of over $100000 \mathrm{~A} / \mathrm{cm}^{2}$ at $5 \mathrm{~K}$ and $5 \mathrm{~T}$ and $20 \mathrm{~K}$ and $2 \mathrm{~T}$ were obtained, comparable to NbTi and HTS respectively. The high performance $\mathrm{SiC}$ doped $\mathrm{MgB}_{2}$ wires will have a great potential to replace the current market leader, $\mathrm{Nb}-\mathrm{Ti}$ and HTS for many practical applications at $5 \mathrm{~K}$ to $25 \mathrm{~K}$ up to $5 \mathrm{~T}$.

\section{ACKNOWLEDGMENT}

The authors thank A. Pan, M. Ionescu, E. W. Collings, M. Sumption, M. Tomsic and R. Neale for their helpful discussion and Australian Research Council, Hyper Tech Research Inc. OH USA and Alphatech International Ltd. for support.

\section{REFERENCES}

[1] S. Jin, H. Mavoori, and R. B. van Dover, "High transport critical current in dense, metal superconductor wire of $\mathrm{MgB}_{2}$," Nature, vol. 411, p. 563, 2001.

[2] S. Soltanian et al., "High transport critical current density at above $30 \mathrm{~K}$ in pure Fe clad $\mathrm{MgB}_{2}$ wire," Physica C, vol. 361, p. 230, 2001.

[3] W. Goldacher, S. I. Schlachter, S. Zimmer, and H. Reiner, "High transport current density in mechanically reinforced $\mathrm{MgB}_{2}$ wire," Supercond. Sci. Technol., vol. 14, p. 787, 2001.

[4] H. L. Suo et al., "Large transport critical current in dense Fe- and Ni-clad $\mathrm{MgB}_{2}$ superconductor tapes," Appl. Phys. Lett., vol. 79, p. 3116, 2001.

[5] G. Grasso et al., "Large transport critical current in unsintered $\mathrm{MgB}_{2}$ superconducting tapes," Appl. Phys. Lett., vol. 79, p. 230, 2001.

[6] C. B. Eom et al., "Thin film magnesium boride superconductor with very high critical current density and enhanced irreversibility field," Nature, vol. 411, p. 558, 2001.

[7] Y. Bugoslavsky et al., "Effective Vortex Pinning in $\mathrm{MgB}_{2}$ thin films," Nature, vol. 411, p. 561, 2001.

[8] Y. Zhao et al., "High critical current density of $\mathrm{MgB}_{2}$ bulk superconductor deped with Ti and sintered at ambient pressure," Appl. Phys. Lett., vol. 79, p. 1154, 2001.

[9] J. Wang et al., "High critical current density and improved irreversibility field in bulk $\mathrm{MgB}_{2}$ made by a scaleable, nanoparticle addition route,", Cond-mat/0 204472.

[10] M. R. Cimberle, M. Novak, P. manfrinetti, and A. Palenzona, "Magnetic characterization of sintered $\mathrm{MgB}_{2}$ samples: Effect of the substitution or doping with Li, Al and Si," Supercond. Sci. Tech., vol. 15, p. 34, 2002.

[11] S. X. Dou, A. V. Pan, S. Zhou, M. Ionescu, H. K. Liu, and P. R. Munroe, "Superconductivity, crtical current density and flux pinning in $\mathrm{MgB}_{2-x}(\mathrm{SiC})_{x / 2}$ superconductor after SiC nanoparticle doping,", Cond-mat/0 207093.

[12] S. X. Dou, S. Soltanian, J. Horvat, X. L. Wang, P. G. Munroe, S. H. Zhou, M. Ionescu, H. K. Liu, and M. Tomsic, "Enhancement of the critical current density and flux pinning of $\mathrm{MgB}_{2}$ superconductor by nano-particle SiC doping,", Cond-Mat/0 207223.

[13] W. Mickelson, J. Cumings, W. Q. Han, and A. Zettl, "Effect of C substitution on superconductivity in magnesium diboride," Phys. Rev. B, vol. 65, p. $052505-1,2002$.

[14] C. Beneduce, H. L. Suo, P. Toulemonde, N. Musolino, and R. Flukiger, "Transport critical current, anisotropy, irreversibility fields and exponential $n$ factors in Fe sheathed $\mathrm{MgB}_{2}$ tapes,", Cond-mat/0 203551. 